Supplement of Biogeosciences, 17, 4025-4042, 2020

https://doi.org/10.5194/bg-17-4025-2020-supplement

(C) Author(s) 2020. This work is distributed under

the Creative Commons Attribution 4.0 License.

(c) (1)

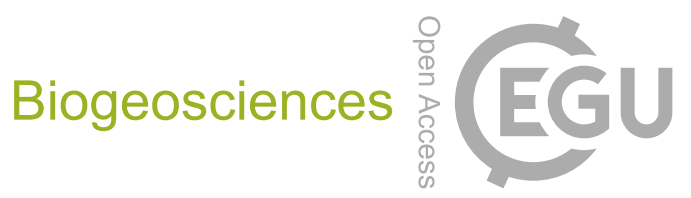

Supplement of

\title{
Environmental controls on ecosystem-scale cold-season methane and car- bon dioxide fluxes in an Arctic tundra ecosystem
}

Dean Howard et al.

Correspondence to: Daniel Obrist (daniel_obrist@uml.edu)

The copyright of individual parts of the supplement might differ from the CC BY 4.0 License. 


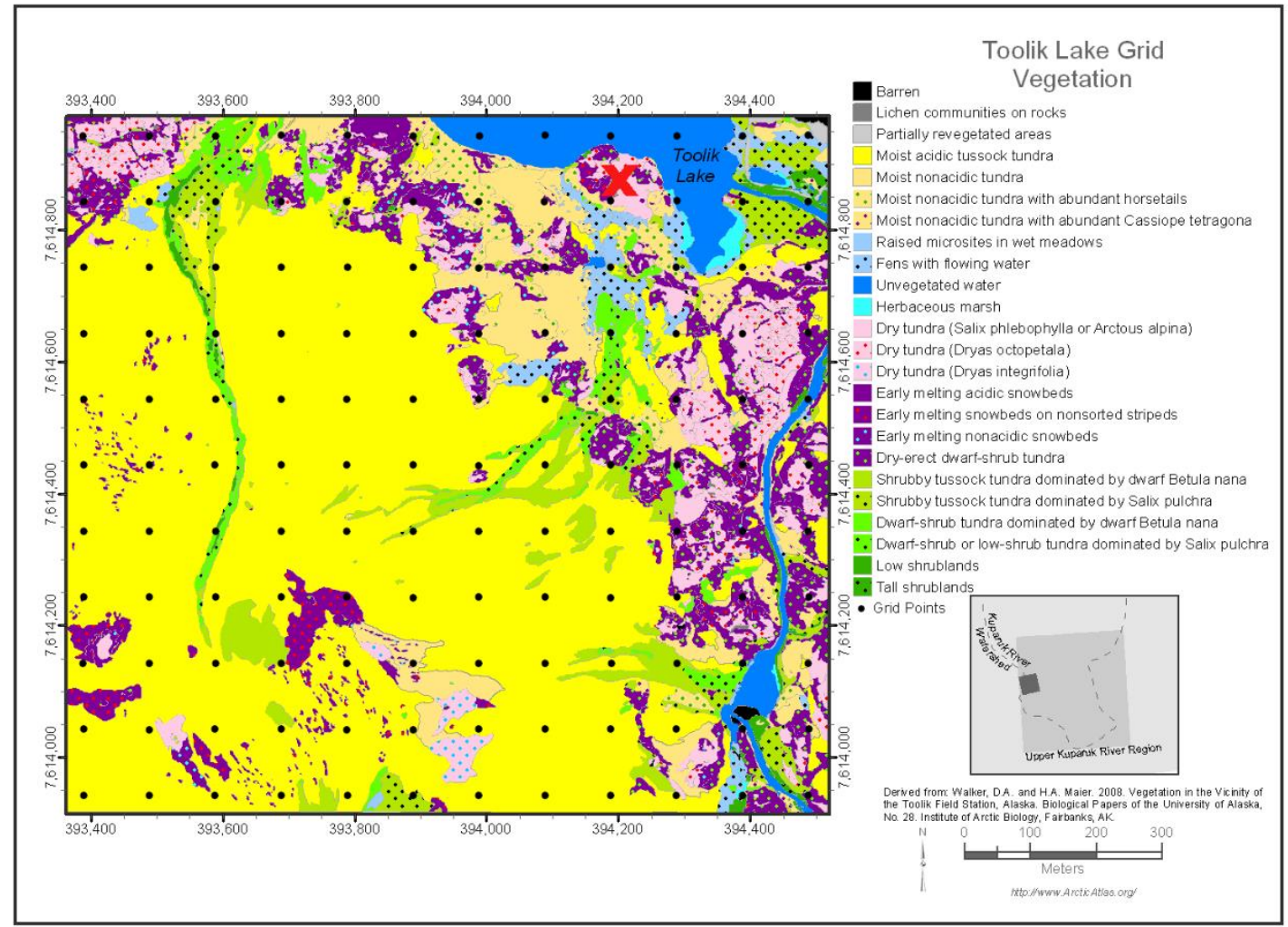

Fig S1: Vegetation map showing major communities in the vicinity of the flux tower. Red ' $X$ ' shows the approximate location of the flux tower. Reproduced with permission from Donald A. (Skip) Walker of University of Alaska Fairbanks. 


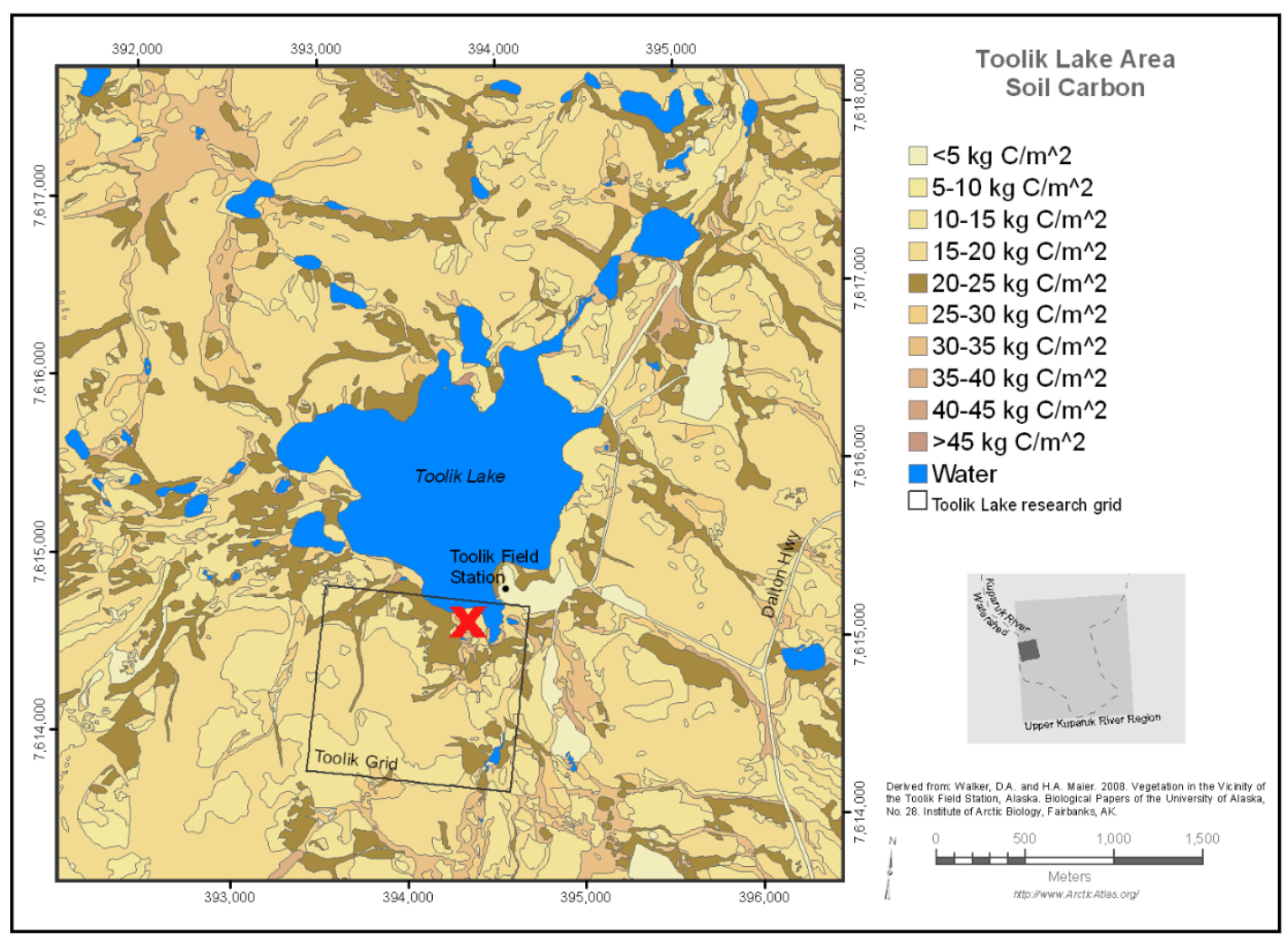

Fig S2: Soil carbon content map for the region around the flux tower. Red ' $X$ ' shows the approximate location of the flux tower. Inset square ("Toolik Grid") shows extent of map in Fig. S1. Reproduced with permission from Donald A. (Skip) Walker of University of Alaska Fairbanks 

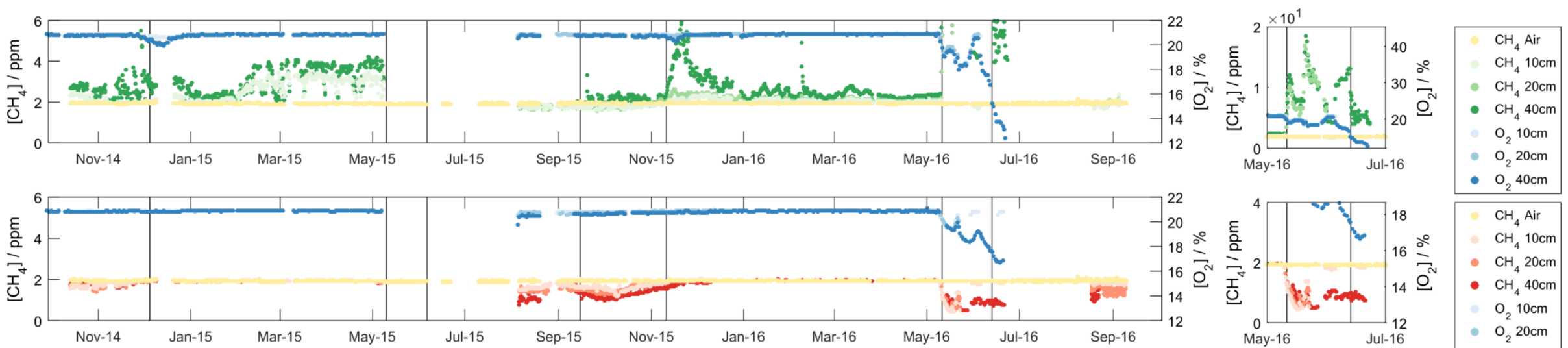

$\mathrm{CH}_{4}$ Air

$\mathrm{CH}_{4} 10 \mathrm{~cm}$

- $\mathrm{CH}_{4} 20 \mathrm{~cm}$

- $\mathrm{CH}_{4} 40 \mathrm{~cm}$

$\mathrm{O}_{2} 10 \mathrm{~cm}$

- $\mathrm{O}_{2} 20 \mathrm{~cm}$
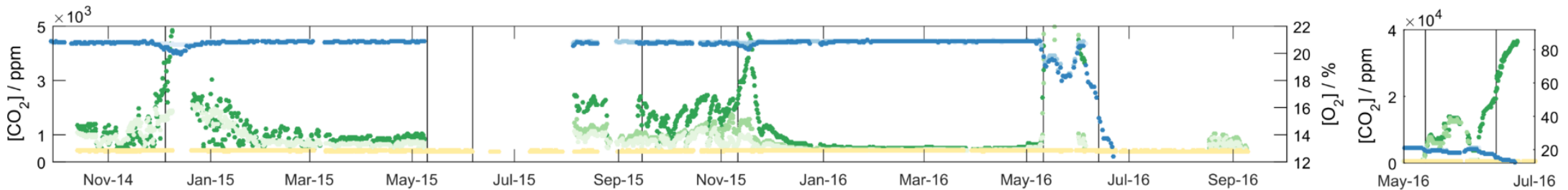

$\mathrm{CO}_{2}$ Air $\mathrm{CO}_{2} 10 \mathrm{~cm}$ - $\mathrm{CO}_{2} 20 \mathrm{~cm}$ - $\mathrm{CO}_{2} 40 \mathrm{~cm}$ $\mathrm{O}_{2} 10 \mathrm{~cm}$ - $\mathrm{O}_{2} 20 \mathrm{~cm}$
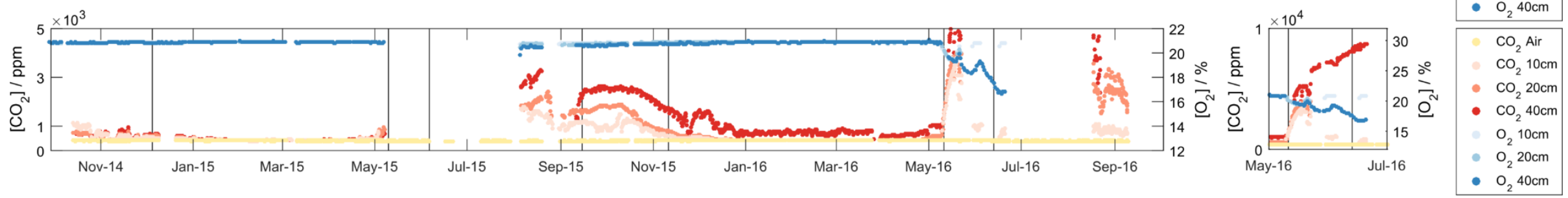

- $\mathrm{O}_{2} 40 \mathrm{~cm}$

Fig S3: Soil pore space gas measurements recorded from the tower profiles. Horizontal panels show, from top to bottom, methane concentrations in the organic profile, methane concentrations in the mineral profile, carbon dioxide concentrations in the organic profile, carbon dioxide concentrations in the mineral profile. Subsets on the right show corresponding measurements during the Year 2 thawing season, when concentrations in most profiles rose significantly higher than during the rest of the year. Note the changing scales on the y-axes. 


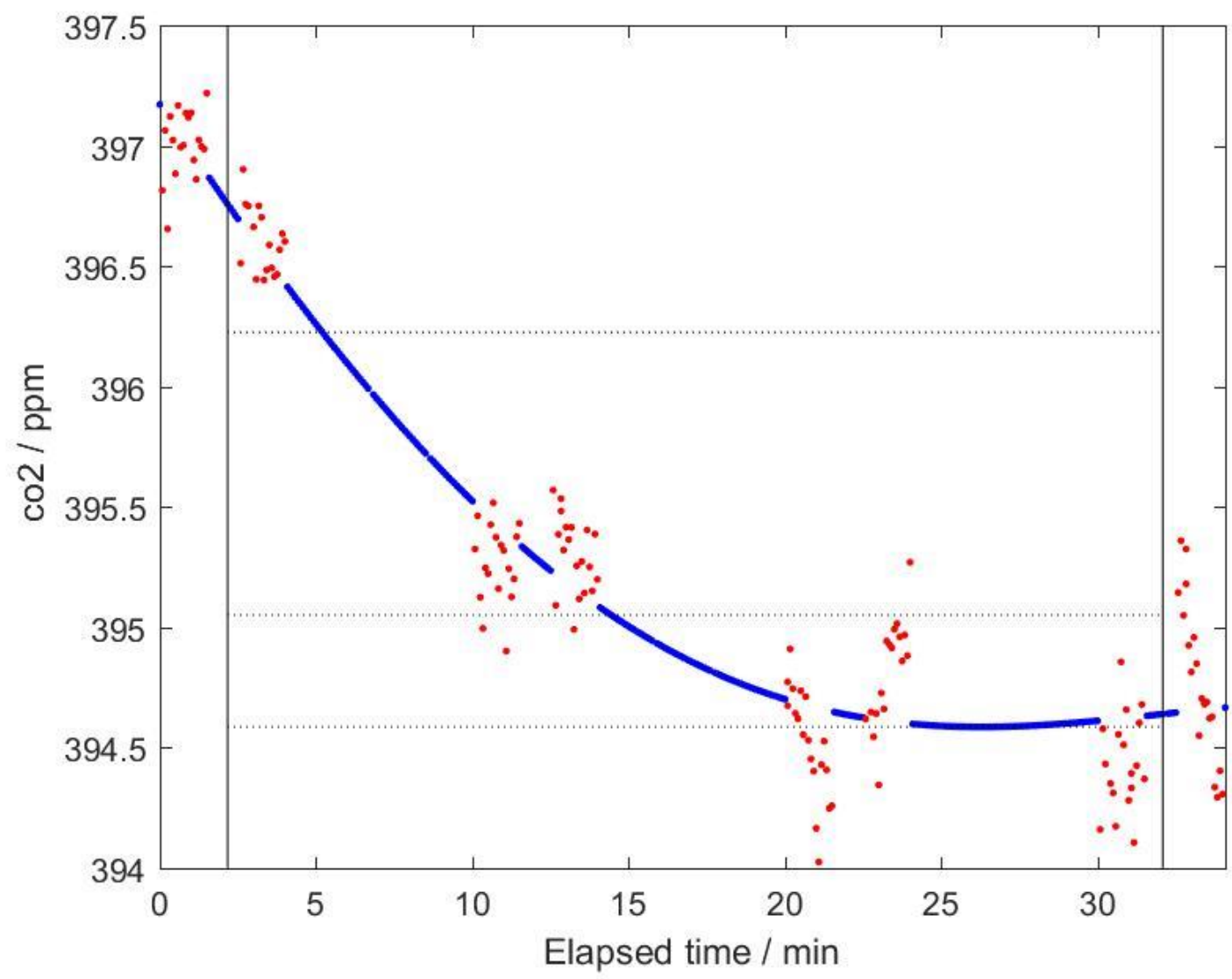

Fig S4: Example of the gap-filling algorithm used to complete concentration data within each averaging period. Red dots represent all measured values used to construct the $4^{\text {th }}$-order polynomial (blue dots). Black vertical lines give the averaging period (30 minutes) - note that red dots outside this averaging period were used to construct the $4^{\text {th }}$-order polynomial but not included in the average. Lower and upper black dotted horizontal lines show the $10^{\text {th }}$ and $90^{\text {th }}$ percentiles of all values (red and blue dots) within the averaging period. Central black dotted horizontal line shows the truncated mean $\left(10^{\text {th }}-90^{\text {th }}\right.$ percentile) that is used as the final value for calculating fluxes. 


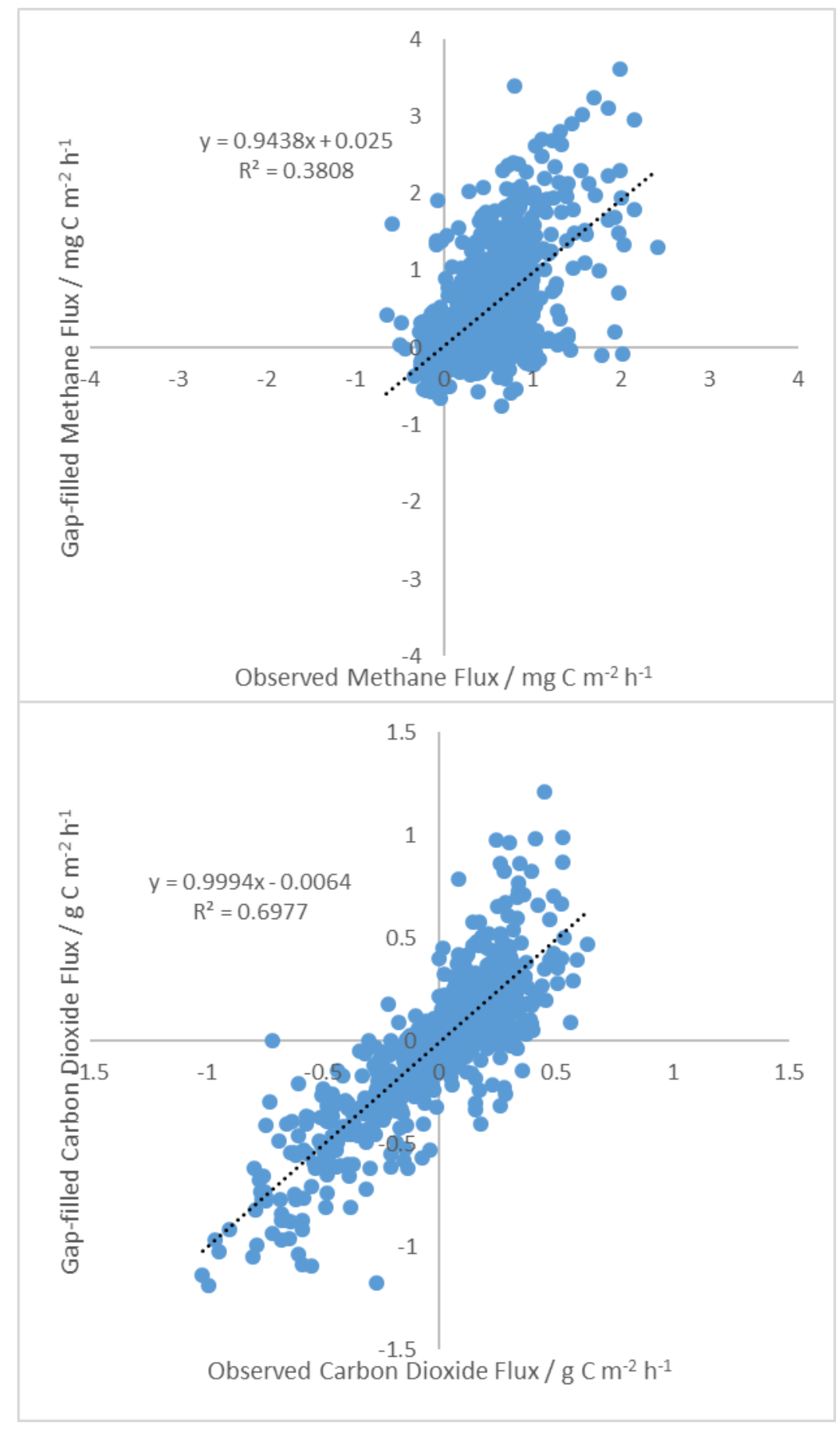

Fig S5: Validation sets showing the efficacy of the gap-filling process. Before gap-filling, $10 \%$ of known values were randomly selected and kept aside as the validation set. These are here compared to values estimated by the gap-filling process, with simple linear regression included. 

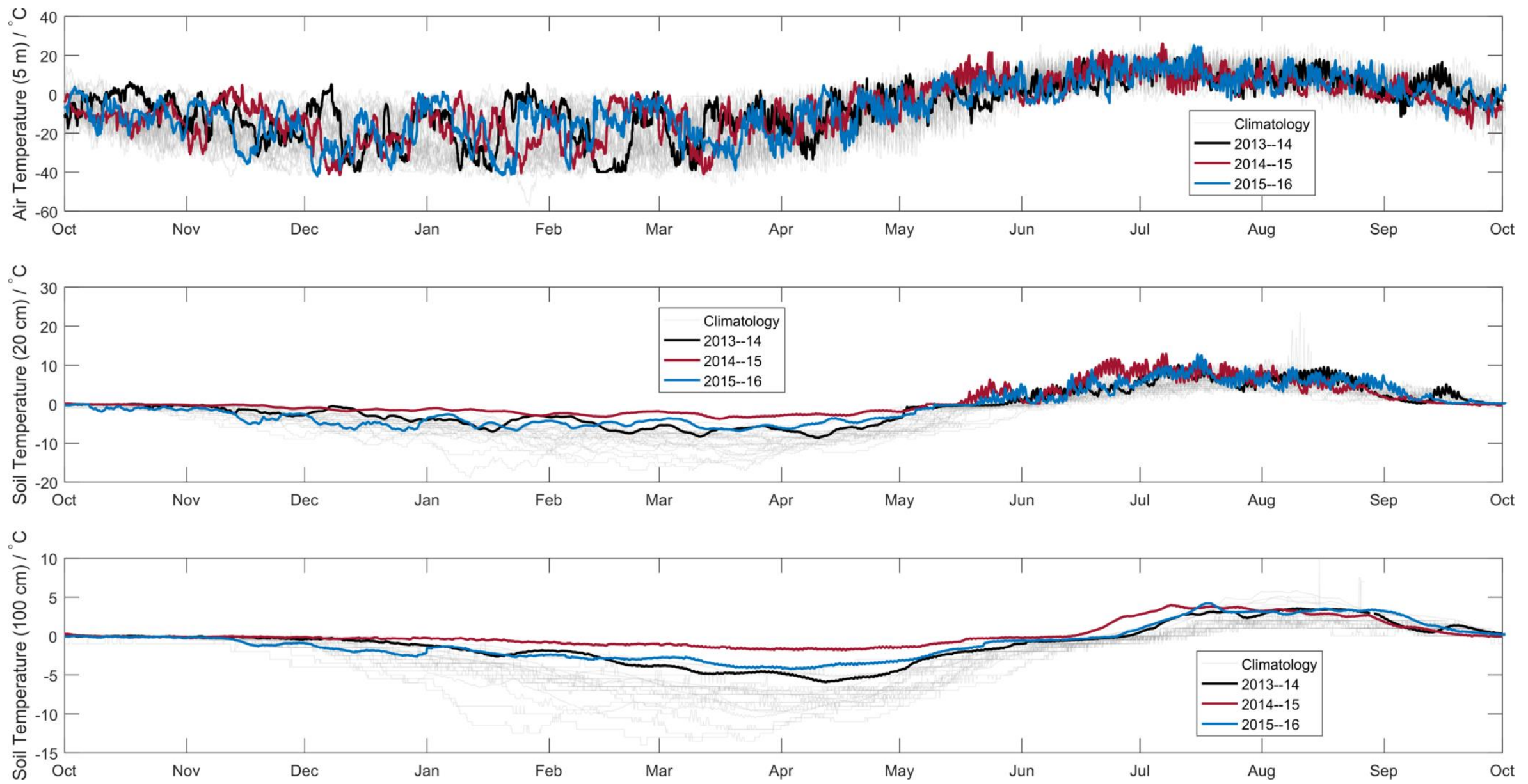

Fig S6: Air ( $5 \mathrm{~m})$ and select soil temperatures as measured at the Toolik Field Station. Grey lines give all values measured between 1988-Oct. 2013. Blue and red lines give values for Year 1 and Year 2 as defined in the text, respectively. Black line gives values for the year preceding the study (2013-14). 

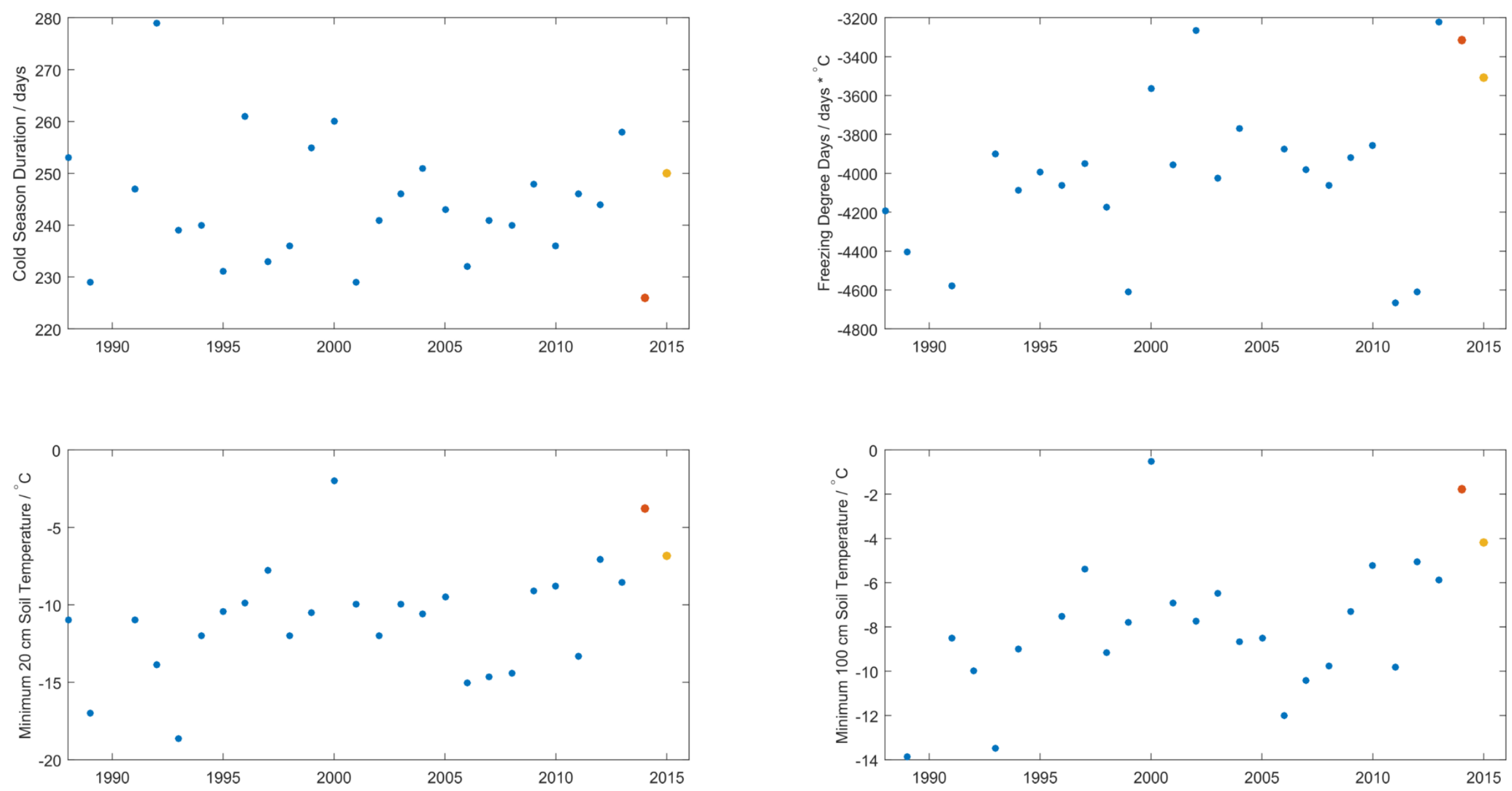

Fig S7: Upper left: cold season durations (calculated using 28-day average $5 \mathrm{~m}$ air temperature - see text), along with total freezing degree days for cold seasons as so defined (upper right). Lower panels show the minimum recorded temperature during the cold season as so defined at depths of $20 \mathrm{~cm}$ (lower left) and $100 \mathrm{~cm}$ (lower right). All data are taken from Toolik Field Station - red dots are for the 2014-15 cold season, yellow for the 2015-16 cold season, blue dots for all other years. 


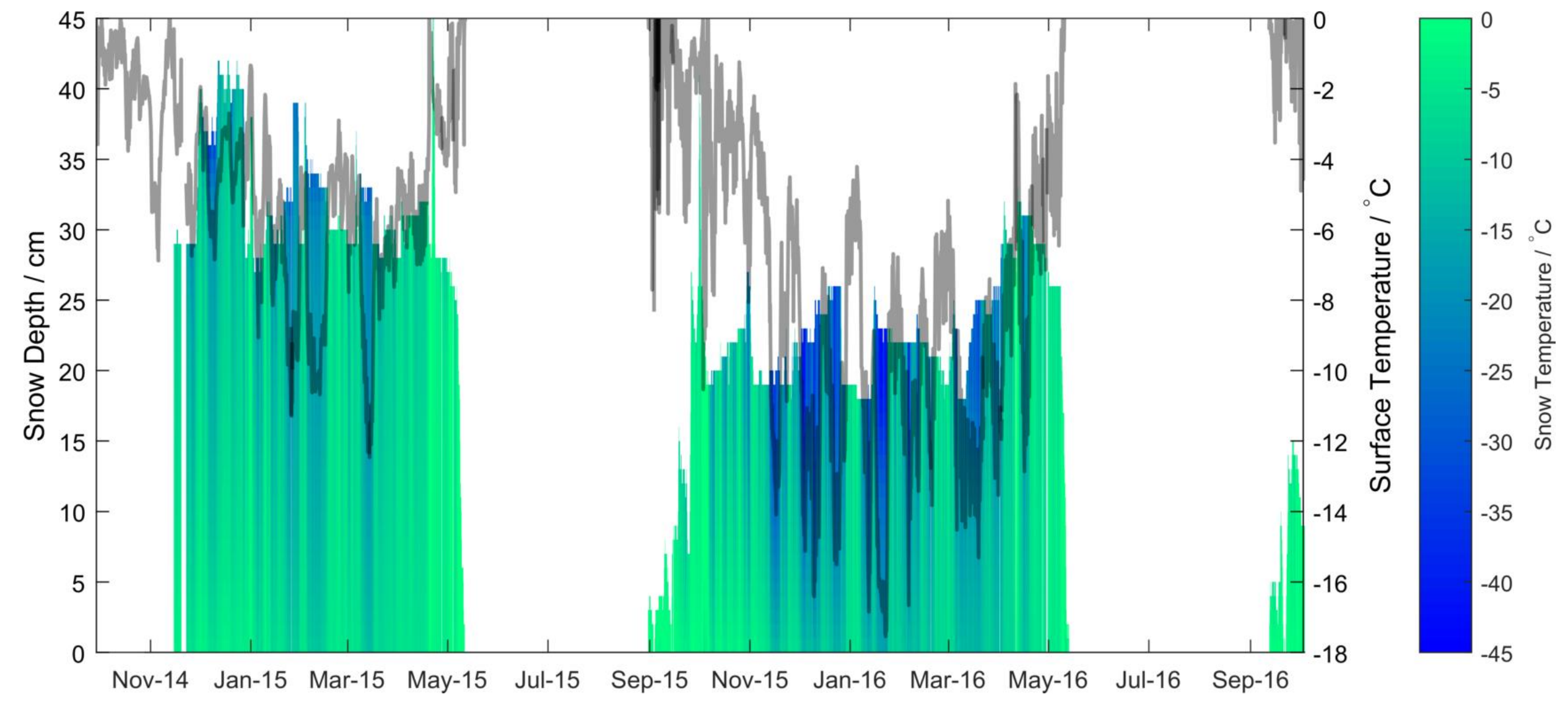

Fig S8: Snow depth (coloured shading, left axis), coloured by temperature as measured by the snow tower. Note that snow depth measurements only began in November 2014 and so values are missing prior to this date. Grey line shows the surface temperature (right axis), as measured at the base of the snow tower. 

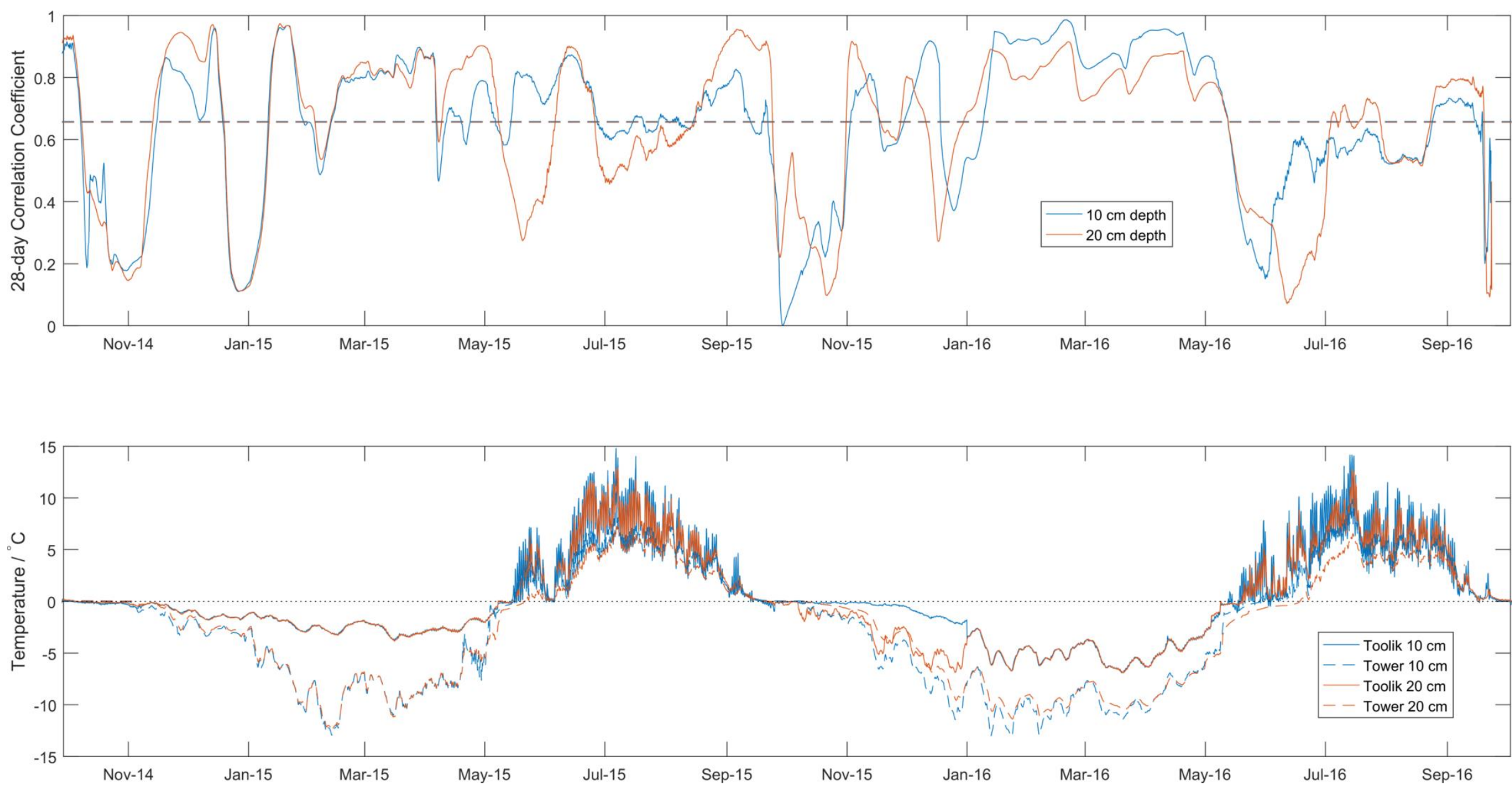

Fig S9: Upper: correlation coefficients between soil temperatures as measured at Toolik Field Station (average of both soil profiles) and close to the flux tower (average of both soil profiles), at $10 \mathrm{~cm}$ and $20 \mathrm{~cm}$ depth. Lower: Actual temperatures measured at $10 \mathrm{~cm}$ and $20 \mathrm{~cm}$ at Toolik Field Station and close to the flux tower. 

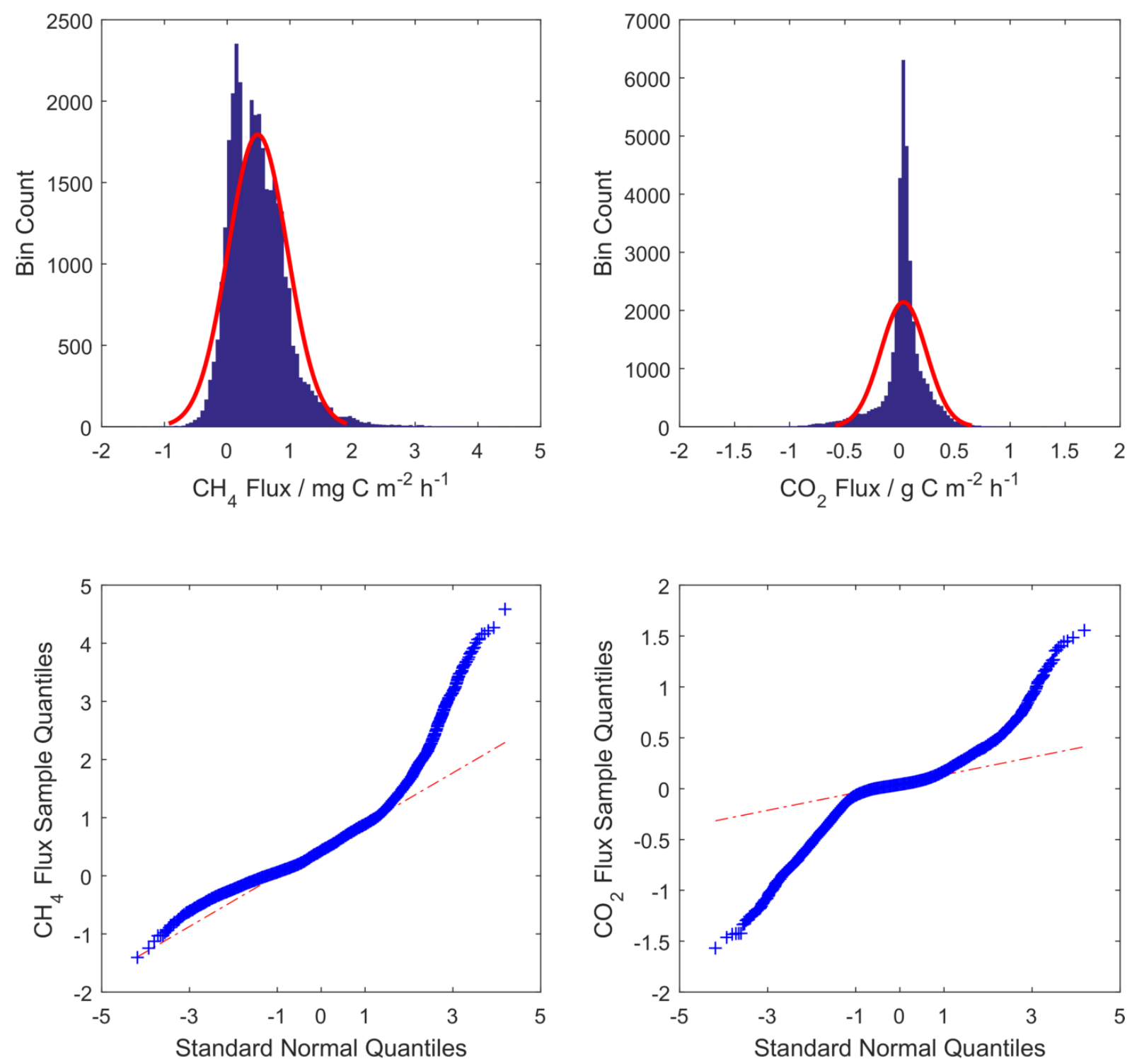

Fig S10: Histograms (upper panels) and quantile plots (lower panels) for all observed methane fluxes (left panels) and carbon dioxide fluxes (right panels). 

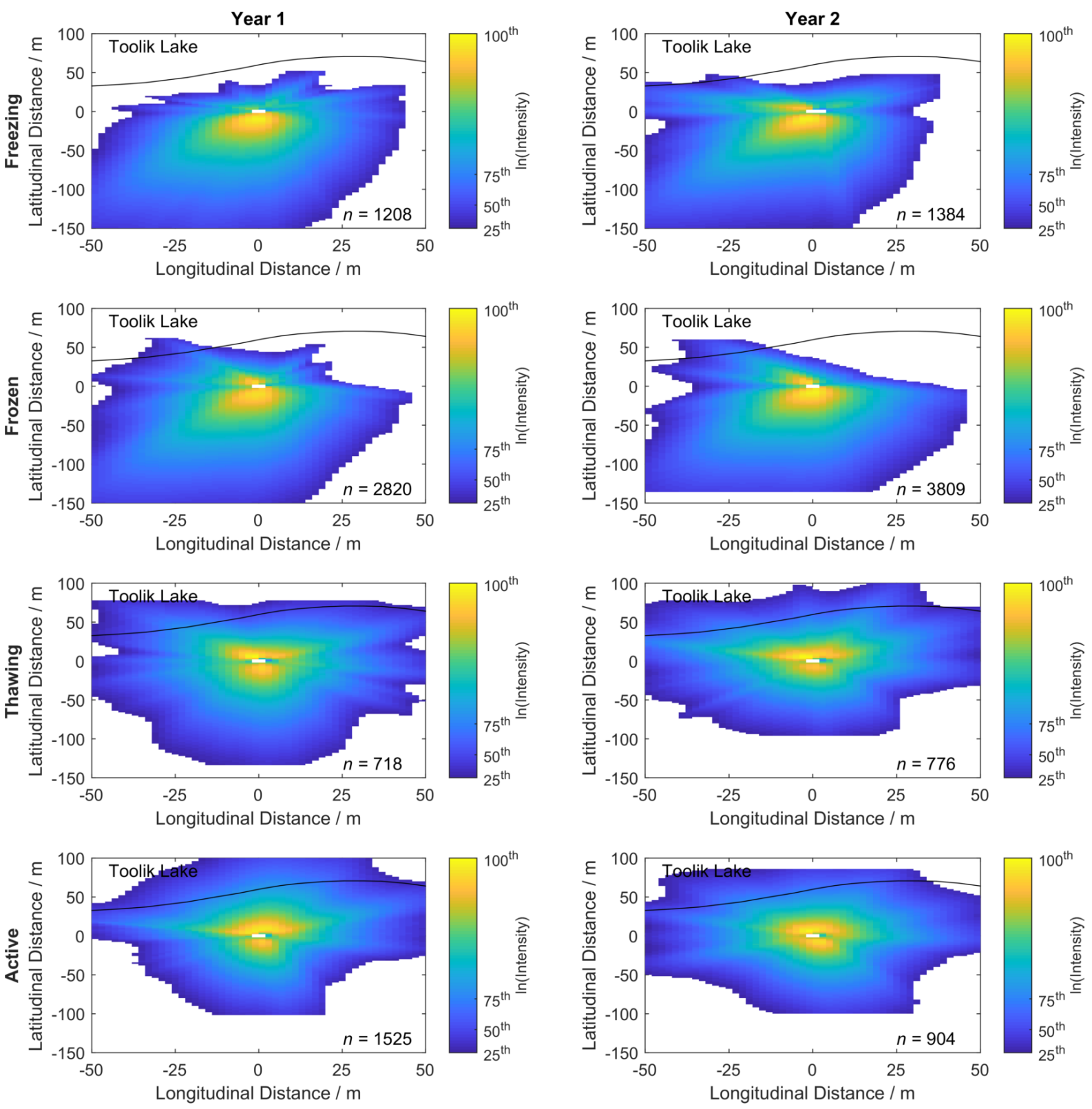

Fig S11: Climatological 2-d footprint analyses as determined using the method given by Kljun et al. (2015) for Year 1 (left panels) and Year 2 (right panels). Labels on the left-hand side give the seasons (as defined in the text) for which the footprints were constructed. Colours represent footprint intensity (unitless) on a logarithmic scale to highlight those values closest to the tower. Values on the colour bars give the percentiles of values shown. 